\title{
Gambaran Kejadian Hemoptisis pada Pasien di Bangsal Paru RSUP Dr. M. Djamil Padang Periode Januari 2011 - Desember 2012
}

Intan Irfa ${ }^{1}$, Irvan Medison ${ }^{2}$, Detty Iryani ${ }^{3}$

\begin{abstract}
Abstrak
Hemoptisis adalah ekspektorasi darah yang berasal dari saluran pernafasan bagian bawah dengan jumlah minimal hingga masif yang dapat membahayakan jiwa. Etiologi hemoptisis seperti infeksi, neoplasma dan kelainan kardiovaskular berbeda kekerapannya di berbagai negara. Di Indonesia dan negara berkembang lainnya, tuberkulosis paru merupakan penyebab utama hemoptisis. Tujuan penelitian ini adalah untuk mengetahui gambaran kejadian hemoptisis pada pasien di bangsal paru RSUP Dr. M. Djamil Padang periode Januari 2011 - Desember 2012. Metode yang digunakan adalah deskriptif secara retrospektif menggunakan data rekam medis pasien rawat inap dengan hemoptisis di bangsal paru RSUP Dr. M. Djamil Padang periode Januari 2011 - Desember 2012. Hasil penelitian menunjukkan bahwa sejak Januari 2011 - Desember 2012 terdapat 103 kejadian hemoptisis dan prevalensi kejadiannya sebesar 3,6\%. Sebagian besar pasien dengan hemoptisis adalah laki-laki (65\%) dengan kelompok usia terbanyak yaitu $31-40$ tahun. Sementara distribusi frekuensi pasien dengan hemoptisis berdasarkan riwayat pendidikan terbanyak yaitu tamat SLTA (32\%), berdasarkan pekerjaan adalah ibu rumah tangga $(29,1 \%)$ dan sebagian besar berdomisili di Kota Padang. Klasifikasi hemoptisis terbanyak adalah hemoptisis sedang (34\%) dengan etiologi utama tuberkulosis paru $(47,6 \%)$. Pada penelitian ini didapat angka kematian pasien sebesar $6,8 \%$ dari total kejadian hemoptisis.
\end{abstract}

Kata kunci: hemoptisis, prevalensi, tuberkulosis

\section{Abstract}

Hemoptysis is expectoration of blood from the lower respiratory tract that varies in amount of blood from small amount to the massive amount and can become threaten of life. The etiology of hemoptysis such as infection, neoplasm and cardiovascular disorder are vary over the world. In Indonesia and other developed countries, pulmonary tuberculosis is a main etiology of hemoptysis. The purpose of this study is to determine the profile of hemoptysis among patients admitted in Pulmonary Department of Dr. M. Djamil Hospital Padang period January 2011 - December 2012. This research was a descriptive survey based on retrospective study design that reviewed the medical record of hospitalized patients with hemoptysis in Pulmonary Department of Dr. M. Djamil Hospital period January 2011 December 2012. The result has shown that since January 2011 - December 2012 there were 103 patients with hemoptysis, and the prevalence of hemoptysis is 3,6\%. Most of patients with hemoptysis are male (65\%) with highest frequency distribution based on age group of patients is $31-40$ years old. While the highest frequency distribution based on patients' history of education is high school diploma (32\%), based on patients' profession is housewife $(29,1 \%)$ and most of patients live in Padang. Moderate hemoptysis (34\%) were the highest frequency distribution based on classification of hemoptysis, with pulmonary tuberculosis as the main etiology (47,6\%). Mortality rate of patients with hemoptysis in this study was $6,8 \%$ of all hemoptysis cases.

Keywords: hemoptysis, prevalence, tuberculosis 


\section{PENDAHULUAN}

Hemoptisis atau batuk darah merupakan masalah kesehatan yang berpotensi menyebabkan kematian karena sulit diprediksi tingkat keparahan dan perkembangan klinisnya. ${ }^{1,2}$ Hemoptisis dalam jumlah yang banyak (masif) termasuk kegawatan medis yang harus mendapatkan penanganan intensif dengan terapi yang tepat. Selain dapat mengganggu kestabilan hemodinamik akibat kehilangan darah dalam jumlah yang banyak, hemoptisis masif juga dapat mengganggu pertukaran gas di alveoli dan menimbulkan komplikasi asfiksia yang tinggi angka mortalitasnya. ${ }^{2,3}$ Meskipun angka kejadian hemoptisis masif hanya 5 - 15\% dari total kasus, hal ini harus selalu ditanggapi sebagai suatu kasus yang mengancam jiwa dan memerlukan penanganan dan manajemen yang efektif. ${ }^{4}$

Etiologi hemoptisis yang diketahui saat ini sangat beragam, tidak hanya infeksi dan kelainan paru, tetapi juga neoplasma, kelainan kardiovaskular, kelainan hematologi ataupun penyakit sistemik. ${ }^{3,5}$ Perbedaan etiologi hemoptisis terkait letak geografis terutama dipengaruhi tingginya angka kejadian tuberkulosis di suatu negara. ${ }^{6}$ Penyebab utama hemoptisis di negara barat adalah keganasan dan kelainan non tuberkulosis lainnya. Berbeda halnya dengan di negara berkembang yang sebagian besar endemik tuberkulosis, penyakit tersebut masih menjadi penyebab utama yang mendasari hemoptisis. ${ }^{6-8}$

Di Indonesia, berdasarkan studi yang dilakukan pada pasien rawat inap dan IGD RS Persahabatan, tuberkulosis paru merupakan penyakit terbanyak yang mendasari hemoptisis. ${ }^{9}$ Indonesia termasuk ke dalam 22 negara yang dikategorikan oleh WHO sebagai High Burden Countries (HBCs) yang sebagian besar adalah negara-negara di Asia dan Afrika dengan endemisitas tuberkulosis (TB) yang tinggi. $^{10}$ Diperkirakan setiap tahun di Indonesia terdapat 528.000 kasus TB baru pada lebih dari $70 \%$ usia produktif, dengan kematian sekitar 91.000 orang. Pengendalian tuberkulosis di Indonesia telah mendekati target Millenium Development Goals (MDGs), yaitu 222 per 100.000 penduduk pada tahun 2015. Walaupun telah banyak kemajuan yang dicapai dalam penanggulangan TB di Indonesia, tetapi tantangan masalah TB ke depan masih besar, terutama dengan meningkatnya perkembangan HIV dan Multi Drugs Resistancy (MDR). ${ }^{11}$ Berdasarkan penelitian di RSUP Dr. M. Djamil Padang, sejak tahun 2005 - 2009 setiap tahunnya tuberkulosis paru tetap menjadi penyebab utama hemoptisis. ${ }^{12}$

Penelitian ini bertujuan untuk mengetahui gambaran kejadian hemoptisis pada pasien di bangsal Paru RSUP Dr. M. Djamil Padang periode Januari 2011 - Desember 2012.

\section{METODE}

Ini merupakan penelitian deskriptif secara retrospektif dengan pendekatan cross-sectional study yang dilakukan sejak bulan Januari 2013 sampai dengan Agustus 2013 di Bagian Rekam Medis dan SMF Paru RSUP Dr. M. Djamil Padang. Subjek penelitian adalah seluruh pasien dengan hemoptisis yang tercatat dalam rekam medis dan dirawat di bangsal paru RSUP Dr. M. Djamil Padang selama periode Januari 2011 - Desember 2012 yang memenuhi kriteria yang ditetapkan. Pengelompokan hemoptisis dalam penelitian ini berdasarkan volume dan frekuensi batuk darah (hemoptisis) yang dicatat menurut anamnesis saat pasien masuk rumah sakit kecuali ada keterangan lain dan disesuaikan dengan sistem klasifikasi yang digunakan di bagian paru RSUP Dr. M. Djamil Padang, yaitu :

a. Hemoptisis ringan: volume batuk darah < 30 $\mathrm{ml} /$ hari.

b. Hemoptisis sedang: volume batuk darah $30-150$ $\mathrm{ml} /$ hari.

c. Hemoptisis berat: volume batuk darah > 150 $\mathrm{ml} /$ hari tetapi tidak memenuhi kriteria hemoptisis massif.

d. Hemoptisis masif:

- Batuk darah $\geq 600 \mathrm{ml}$ dalam 24 jam dan dalam pengamatan batuk darah tidak berhenti.

- Batuk darah $\geq 250 \mathrm{ml}$ tetapi kurang dari $600 \mathrm{ml}$ dalam 24 jam dan pemeriksaan laboratorium menunjukkan hemoglobin kurang dari $10 \mathrm{gr} / \mathrm{dl}$, dalam pengamatan batuk darah tetap berlangsung.

- Batuk darah > $250 \mathrm{ml}$ tetapi kurang dari $600 \mathrm{ml}$ dalam 24 jam dan dari pemeriksaan laboratorium 
hemoglobin lebih dari $10 \mathrm{gr} / \mathrm{dl}$, tetapi dalam pengamatan 48 jam dengan pengobatan konservatif batuk darah tidak berhenti.

\section{HASIL}

Dalam periode Januari 2011 sampai dengan Desember 2012 total kasus rawat inap di bangsal paru RSUP Dr. M. Djamil Padang adalah 2.860 kasus, dengan rincian 1.416 kasus selama tahun 2011 dan 1.444 kasus selama tahun 2012. Total kejadian hemoptisis selama kurun waktu dua tahun tersebut sebanyak 103 kasus. Sebelumnya, 9 kasus telah dieksklusikan karena ketidak-tersediaan data pendukung penelitian.

Jumlah kejadian hemoptisis pada tahun 2011 adalah 38 kasus atau 1,3\% dari total kasus rawat inap di bangsal paru selama Januari 2011 - Desember 2012, sementara pada tahun 2012 terdapat 65 kasus hemoptisis atau 2,3\% dari total kasus rawat inap di bangsal paru selama Januari 2011 - Desember 2012. Secara keseluruhan didapatkan prevalensi hemoptisis pada pasien di bangsal paru RSUP Dr. M. Djamil Padang periode Januari 2011 - Desember 2012 sebesar $3,6 \%$.

Tabel 1. Karakteristik Pasien dengan Hemoptisis Di Bangsal Paru RSUP Dr. M. Djamil

\begin{tabular}{|c|c|}
\hline Karakteristik & Jumlah \\
\hline Jumlah subjek penelitian & $\overline{103}$ \\
\hline Usia min. - maks. & $15-82$ tahun \\
\hline Rata-rata usia ( \pm SD) & $43,3( \pm 16,24)$ tahun \\
\hline \multicolumn{2}{|l|}{ Jenis kelamin } \\
\hline Laki-laki & $67(65 \%)$ \\
\hline Perempuan & $36(35 \%)$ \\
\hline \multicolumn{2}{|l|}{ Riwayat Pendidikan } \\
\hline Tidak tamat SD & $6(5,8 \%)$ \\
\hline Tamat SD & $17(16,5 \%)$ \\
\hline Tamat SLTP & $23(22,3 \%)$ \\
\hline Tamat SLTA & $33(32 \%)$ \\
\hline Tamat Akademi/Universitas & $8(7,8 \%)$ \\
\hline Tidak diketahui & $16(15,5 \%)$ \\
\hline Karakteristik & Jumlah \\
\hline Pelajar/Mahasiswa & $6(5,8 \%)$ \\
\hline Ibu rumah tangga & $30(29,1 \%)$ \\
\hline Buruh & $19(18,4 \%)$ \\
\hline Wiraswasta & $10(9,7 \%)$ \\
\hline Petani & $12(11,7 \%)$ \\
\hline PNS & $3(2,9 \%)$ \\
\hline Pegawai swasta & $8(7,8 \%)$ \\
\hline Nelayan & $4(3,9 \%)$ \\
\hline Pensiunan & $7(6,8 \%)$ \\
\hline Tidak bekerja & $4(3,9 \%)$ \\
\hline
\end{tabular}

pasien dengan hemoptisis adalah 43,3 tahun, dengan distribusi frekuensi subjek penelitian berdasarkan jenis kelamin menunjukkan bahwa jumlah kejadian hemoptisis pada pasien laki-laki lebih banyak daripada pasien perempuan, yaitu masing-masing 67 orang (65\%) dan 36 orang (35\%). Sementara distribusi rekuensi subjek penelitian berdasarkan riwayat pendidikan yang terbanyak adalah tamatan SLTA, yaitu 33 kasus (32\%) dan paling sedikit adalah dengan riwayat pendidikan tidak tamat SD, sebanyak 6 kasus (5,8\%). Untuk pekerjaan, distribusi frekuensi subjek penelitian terbanyak adalah ibu rumah tangga, yaitu 30 orang atau $29,1 \%$ dari total kejadian hemoptisis.

Tabel 2. Distribusi Frekuensi Subjek Penelitian Berdasarkan Usia

\begin{tabular}{lcc}
\hline \multicolumn{1}{c}{ Usia } & Frekuensi & $\begin{array}{c}\text { Persentase dari Total Pasien } \\
\text { dengan Hemoptisis (\%) }\end{array}$ \\
\hline$\leq 20$ tahun & 5 & 4,9 \\
$21-30$ tahun & 21 & 20,4 \\
$31-40$ tahun & 25 & 24,3 \\
$41-50$ tahun & 18 & 17,5 \\
$51-60$ tahun & 20 & 19,4 \\
$>60$ tahun & 14 & 13,6 \\
\hline Total & $\mathbf{1 0 3}$ & $\mathbf{1 0 0}$ \\
\hline
\end{tabular}

Distribusi frekuensi berdasarkan usia didapatkan kejadian hemoptisis terbanyak pada kelompok usia 31 - 40 tahun, yaitu sebanyak 25 kasus $(24,3 \%)$.

Tabel 3. Distribusi Frekuensi Subjek Penelitian Berdasarkan Tempat (Domisili)

\begin{tabular}{lcc}
\hline \multicolumn{1}{c}{ Tempat (Domisili) } & Frekuensi & $\begin{array}{c}\text { Persentase dari } \\
\text { Total Pasien } \\
\text { dengan } \\
\text { Hemoptisis (\%) }\end{array}$ \\
\hline Kota Padang & 66 & 64,1 \\
Kota Bukittinggi & 1 & 1 \\
Kota Pariaman & 5 & 4,9 \\
Kota Solok & 1 & 1 \\
Kab. Pesisir Selatan & 3 & 2,9 \\
Kab. Pasaman & 3 & 2,9 \\
Kab. Agam & 1 & 1 \\
Kab. Kep. Mentawai & 1 & 1 \\
Kab. Padang Pariaman & 4 & 3,9 \\
Kab. Lima Puluh Kota & 2 & 1,9 \\
Kab. Solok Selatan & 3 & 2,9 \\
Kab. Tanah Datar & 1 & 1 \\
Kab. Sawahlunto Sijunjung & 7 & 6,8 \\
Kab. Dharmasraya & 1 & 1 \\
Luar Sumatra Barat & 4 & 3,9 \\
\hline Total & $\mathbf{1 0 3}$ & \\
\hline
\end{tabular}


Dari tabel 3 dapat diketahui bahwa distribus frekuensi subjek penelitian berdasarkan tempat atau domisili terbanyak adalah dari Kota Padang, yaitu pada 66 kasus hemoptisis $(64,1 \%)$.

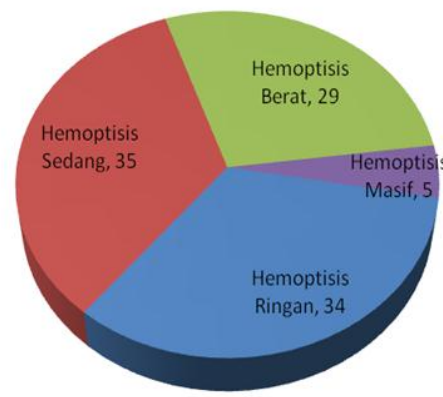

Diagram 1. Distribusi Frekuensi Subjek Penelitian Berdasarkan Klasifikasi Hemoptisis

Diagram 1 menggambarkan distribusi frekuensi subjek penelitian berdasarkan klasifikasi hemoptisis yang terbanyak adalah hemoptisis sedang, sebanyak 35 kasus atau $34 \%$ dari seluruh kejadian hemoptisis.

Tabel 4. Distribusi Frekuensi Subjek Penelitian Berdasarkan Penyakit yang Mendasari Hemoptisis

\begin{tabular}{lcc}
\hline $\begin{array}{c}\text { Penyakit yang } \\
\text { Mendasari }\end{array}$ & Frekuensi & $\begin{array}{c}\text { Persentase dari Total } \\
\text { Pasien dengan } \\
\text { Hemoptisis (\%) }\end{array}$ \\
\hline TB paru & 49 & 47,6 \\
Bekas TB paru & 11 & 10,7 \\
Susp. karsinoma & 14 & 13,6 \\
bronkogenik & & \\
Karsinoma & 2 & 1,9 \\
bronkogenik & 10 & 9,7 \\
Bronkiektasis & 9 & 8,7 \\
CAP & 4 & 3,9 \\
Aspergiloma & 3 & 2,9 \\
Abses paru & 1 & 1 \\
Lain-lain & $\mathbf{1 0 3}$ & $\mathbf{1 0 0}$ \\
\hline Total & &
\end{tabular}

Distribusi frekuensi subjek penelitian berdasarkan penyakit yang mendasari (etiologi) hemoptisis terbanyak adalah TB paru, yaitu sebanyak 49 kasus $(47,6 \%)$. Lain-lain yang dimaksud dalam tabel 4 adalah kasus hemoptisis dengan diagnosis kerja Limfoma Malignum Hodgkin.

Angka kematian dari seluruh pasien dengan hemoptisis yang dirawat di bangsal paru RSUP Dr. M. Djamil Padang selama periode Januari 2011 -
Desember 2012 adalah 6,8\%. Keterangan diagnosis akhir penyakit serta derajat hemoptisis yang dialaminya dijelaskan pada tabel berikut:

Tabel 5. Diagnosis Akhir Penyakit dan Klasifikasi Hemoptisis pada Pasien Hemoptisis yang Meninggal Dunia

\begin{tabular}{ccc}
\hline $\begin{array}{c}\text { Pasien } \\
\text { Duninggal }\end{array}$ & $\begin{array}{c}\text { Diagnosis Akhir } \\
\text { Penyakit }\end{array}$ & $\begin{array}{c}\text { Klasifikasi } \\
\text { Hemoptisis }\end{array}$ \\
\hline Pasien 1 & $\begin{array}{c}\text { Karsinoma } \\
\text { bronkogenik }\end{array}$ & Hemoptisis ringan \\
Pasien 2 & Bekas TB paru & Hemoptisis sedang \\
Pasien 3 & TB paru & Hemoptisis masif \\
Pasien 4 & TB paru & Hemoptisis ringan \\
Pasien 5 & Susp. Karsinoma & Hemoptisis berat \\
Pasien 6 & bronkogenik & Hemoptisis ringan \\
Pasien 7 & TB paru & Hemoptisis ringan \\
\hline
\end{tabular}

\section{PEMBAHASAN}

Penelitian dilakukan terhadap pasien dengan hemoptisis yang dirawat di bangsal paru RSUP Dr. M. Djamil Padang selama periode Januari 2011 Desember 2012. Terdapat 103 kejadian hemoptisis dengan prevalensi terhadap total kasus rawat inap selama periode tersebut sebesar $3,6 \%$, dan ada peningkatan prevalensi antara tahun 2011 dengan 2012 pada penelitian ini, karena dari etiologi hemoptisis juga terjadi peningkatan yang signifikan terutama pada kasus suspek karsinoma bronkogenik dan bronkiektasis, yang merupakan penyakit kronis progresif. Perbandingan pasien laki-laki dan perempuan yang mengalami hemoptisis pada penelitian ini yaitu 1,8:1. Hasil penelitian ini hampir sama dengan penelitian Hirshberg dkk. yang mendapatkan perbandingan pasien laki-laki dan perempuan sebesar $1,56: 1^{13}$

Berdasarkan usia pasien didapatkan rata-rata usia 43,3 \pm 16,2 tahun, yang hampir serupa dengan hasil penelitian Abal dengan usia rata-rata 42,2 tahun. ${ }^{7}$ Namun dari studi di Israel ditemukan rata-rata usia pasien yang berbeda, yaitu $58 \pm 17$ tahun. Perbedaan tersebut dapat saja terjadi apabila penyakit terbanyak yang mendasari kejadian hemoptisis pada masingmasing penelitian juga berbeda, dimana pada penelitian tersebut bronkiektasis adalah penyebab utama hemoptisis. $^{13}$ 
Dalam penelitian ini, penyakit terbanyak yang mendasari terjadinya hemoptisis adalah TB paru, sebanyak 49 kasus atau $47,6 \%$ dari total kejadian hemoptisis di bangsal paru RSUP Dr. M. Djamil selama Januari 2011 - Desember 2012. Penelitian sebelumnya oleh Russilawati, $d k k$ di RSUP Dr. M. Djamil juga mendapatkan TB aktif sebagai penyebab utama hemoptisis, dengan persentase $43 \%$ dari total kasus hemoptisis selama 5 tahun, diikuti oleh bekas TB $22 \%$ dan kanker paru $10 \%{ }^{12}$ Pada penelitian ini ditemukan bekas TB paru sebagai penyakit yang mendasari hemoptisis ditemukan sebanyak 11 kasus $(10,7 \%$ dari total kejadian hemoptisis). Etiologi hemoptisis terbanyak kedua adalah suspek karsinoma bronkogenik sebanyak 14 kasus atau 13,6\% dari total kejadian hemoptisis, dan karsinoma bronkogenik ada 2 kasus (1,9\%). Hasil yang didapat cukup berbeda dengan hasil penelitian sebelumnya, hal ini dapat terjadi jika terdapat perbedaan tingkat keakuratan diagnostik histopatologi yang dilakukan sebagai gold standard dalam pemeriksaan suatu karsinoma. Karsinoma bronkogenik adalah kanker paru yang menjadi etiologi utama dari seluruh kasus. ${ }^{14}$

Penelitian Prasad di India juga menunjukkan tuberkulosis sebagai penyebab utama hemoptisis $(79,2 \%)$ yang merupakan gabungan kasus etiologi TB aktif dan bekas TB, diikuti karsinoma bronkogenik sebanyak $5 \% .^{8}$ Kondisi yang serupa juga didapat dari penelitian Shigemura di China yang menyatakan tuberkulosis sebagai etiologi utama hemoptisis (55\%), sementara kanker paru hanya menyebabkan $6 \%$ hemoptisis dari total kasus. ${ }^{15}$ Rendahnya persentase kanker paru di negara-negara berkembang dapat disebabkan oleh tingginya angka kejadian hemoptisis yang disebabkan oleh tuberkulosis ataupun karena kurang lengkapnya sarana diagnostik yang tersedia sehingga etiologi hemoptisisnya dimasukkan dalam kategori tidak diketahui (unknown). ${ }^{8}$ Negara-negara di Asia dengan kepadatan penduduk yang tinggi seperti China, India, Indonesia, Bangladesh dan Pakistan merupakan sumber kasus tuberkulosis terbanyak di dunia, yaitu sebesar $48 \%{ }^{16}$

Lain halnya dengan kasus hemoptisis di negara-negara Eropa yang cenderung rendah insiden tuberkulosisnya. Studi Valipour di Austria terhadap pasien dengan life-threatening hemoptysis menunjukkan kanker paru sebagai penyakit yang paling banyak menyebabkan hemoptisis, yaitu pada 20 kasus (35\%), dan TB paru sebagai penyebab terbanyak kedua sebesar $23 \%{ }^{17}$

Hasil berbeda juga dapat terlihat pada penelitian Fartoukh di Perancis, yang menyimpulkan bronkiektasis sebagai etiologi utama hemoptisis, dengan persentase $40 \%$ dari total kasus hemoptisis. ${ }^{18}$ Pada penelitian ini didapatkan bronkiektasis hanya terjadi pada $9,7 \%$ kasus hemoptisis.

Tabel 6. Keterkaitan Etiologi Hemoptisis dengan Klasifikasi Hemoptisis

\begin{tabular}{|c|c|c|c|c|c|}
\hline \multirow{2}{*}{$\begin{array}{c}\text { Etiologi } \\
\text { Hemoptisis }\end{array}$} & \multicolumn{4}{|c|}{ Klasifikasi Hemoptisis } & \multirow{2}{*}{ Tota } \\
\hline & Ringan & Sedang & Berat & Masif & \\
\hline TB paru & 11 & 18 & 17 & 3 & 49 \\
\hline Bekas TB paru & 1 & 6 & 3 & 1 & 11 \\
\hline $\begin{array}{l}\text { Susp. Karsinoma } \\
\text { bronkogenik }\end{array}$ & 11 & 2 & 1 & - & 14 \\
\hline $\begin{array}{l}\text { Karsinoma } \\
\text { bronkogenik }\end{array}$ & 2 & - & - & - & 2 \\
\hline Bronkiektasis & 1 & 3 & 6 & - & 10 \\
\hline CAP & 5 & 2 & 1 & 1 & 9 \\
\hline Aspergiloma & 1 & 2 & 1 & - & 4 \\
\hline Abses paru & 2 & 1 & - & - & 3 \\
\hline Lain-lain & 1 & - & - & - & 1 \\
\hline Total & 35 & 34 & 29 & 5 & 103 \\
\hline
\end{tabular}

Dinilai dari derajat beratnya, klasifikasi hemoptisis yang terbanyak dalam penelitian ini adalah hemoptisis sedang, sebanyak 35 kasus (34\% dari total kejadian hemoptisis) yang didominasi penyakit TB paru. Hasil serupa didapatkan dari penelitian Prasad, dengan dua pertiga dari total kasus hemoptisis yang terjadi adalah derajat sedang (moderate hemoptysis), dan $94 \%$ dari yang tergolong hemoptisis sedang tersebut disebabkan oleh penyakit TB paru. ${ }^{8}$

TB paru merupakan etiologi terbanyak di setiap klasifikasi hemoptisis. Selain itu, terdapat 5 kasus hemoptisis masif atau 4,9\% dari seluruh kejadian hemoptisis yang termasuk sebagai kegawatan paru. Kondisi serupa dinyatakan dalam literatur lain yang jumlah kasus hemoptisis masifnya tergolong sedikit, sekitar $5-15 \%$ dari episode hemoptisis. ${ }^{4}$ Namun kejadian hemoptisis sulit diprediksi, tidak tertutup kemungkinan bagi pasien yang awalnya datang hanya dengan keluhan batuk darah ringan sampai sedang di kemudian hari datang dengan hemoptisis berat bahkan masif. ${ }^{2}$ 
Kecenderungan terjadinya rekurensi atau hemoptisis berulang tergantung dari etiologi atau penyakit yang mendasari hemoptisisnya.Seperti halnya dalam penelitian ini, terdapat empat pasien yang datang untuk kedua kalinya dengan keluhan hemoptisis. Hemoptisis berulang lebih banyak terjadi pada pasien bronkiektasis, bekas TB paru dan aspergiloma. Jika kelainannya terlokalisir, untuk mencegah rekurensi pada pasien dengan hemoptisis yang menderita bronkiektasis dan aspergiloma dapat dilakukan pembedahan bila tidak terdapat kontraindikasi, namun bila ada, dapat dilakukan alternatif terapi spesifik yaitu embolisasi arteri bronkial yang tingkat keberhasilannya tinggi (88\%), ${ }^{2,4}$ Ini menjadi terapi pilihan juga bagi pasien dengan hemoptisis bekas TB paru yang tidak dapat diatasi dengan terapi konservatif saja.

Tabel 7. Keterkaitan Etiologi Hemoptisis dengan Kelompok Usia Pasien dengan Hemoptisis

\begin{tabular}{lccccccc}
\hline \multirow{2}{*}{$\begin{array}{l}\text { Etiologi } \\
\text { Hemoptisis }\end{array}$} & $\leq$ & $\mathbf{2 1 -}$ & $\mathbf{3 1 -}$ & $\mathbf{4 1 -}$ & $\mathbf{5 1 -}$ & $>$ & Total \\
\cline { 2 - 6 } & $\mathbf{2 0}$ & $\mathbf{3 0}$ & $\mathbf{4 0}$ & $\mathbf{5 0}$ & $\mathbf{6 0}$ & $\mathbf{6 0}$ & \\
\hline TB paru & 3 & 14 & 11 & 9 & 6 & 6 & $\mathbf{4 9}$ \\
Bekas TB paru & - & - & 3 & 3 & 1 & 4 & $\mathbf{1 1}$ \\
Susp. & & & & & & & \\
Karsinoma & - & - & - & 3 & 8 & 3 & $\mathbf{1 4}$ \\
bronkogenik & & & & & & & \\
Karsinoma & - & 1 & - & - & - & 1 & $\mathbf{2}$ \\
bronkogenik & & & & & & & \\
Bronkiektasis & - & 1 & 4 & 1 & 4 & - & $\mathbf{1 0}$ \\
CAP & 2 & 4 & 2 & 1 & - & - & $\mathbf{9}$ \\
Aspergiloma & - & - & 3 & - & 1 & - & $\mathbf{4}$ \\
Abses paru & - & 1 & 1 & 1 & - & - & $\mathbf{3}$ \\
Lain-lain & - & - & 1 & - & - & - & $\mathbf{1}$ \\
\hline Total & $\mathbf{5}$ & $\mathbf{2 1}$ & $\mathbf{2 5}$ & $\mathbf{1 8}$ & $\mathbf{2 0}$ & $\mathbf{1 4}$ & $\mathbf{1 0 3}$ \\
\hline
\end{tabular}

Pada penelitian ini, kelompok usia terbanyak yang mengalami hemoptisis adalah 31 - 40 tahun, dengan jumlah kasus $25(24,1 \%$ dari total kasus hemoptisis). Hasil yang berbeda didapatkan oleh Bhatta, dengan kelompok usia terbanyak yang mengalami hemoptisis di usia 21 - 30 tahun (29,5\%), sementara kelompok usia 31 - 40 tahun ada di urutan dua, sebanyak 19,7\% dari total kasus hemoptisis. ${ }^{19}$ Penyakit TB paru mendominasi hemoptisis hampir di semua kelompok usia. Pada usia 51 - 60 tahun, hemoptisis lebih banyak disebabkan suspek karsinoma bronkogenik. Keganasan seperti kanker paru (karsinoma bronkogenik) memang lebih tinggi risikonya pada orang berusia 40 tahun ke atas. ${ }^{20}$ Menurut Boyd, kanker paru sebagai penyebab hemoptisis lebih sering ditemukan pada pasien usia lanjut dibandingkan pada usia kurang dari 35 tahun. ${ }^{21}$

Hemoptisis pada laki-laki lebih banyak terjadi pada kelompok usia 21 - 30 tahun dan 31 - 40 tahun yang merupakan usia produktif, masing-masing sebanyak 16 kasus. Sementara pada perempuan, kelompok usia terbanyak yang mengalami hemoptisis adalah 31 - 40 tahun, dan lebih dari $80 \%$ pasien perempuan dalam penelitian ini adalah ibu rumah tangga. Jika dilihat dari jumlahnya, pasien laki-laki lebih banyak dibandingkan pasien perempuan, tetapi karena distribusi frekuensi pekerjaannya lebih beragam dan merata, sehingga dari aspek pekerjaan, ibu rumah tangga $(29,1 \%)$ tetap teridentifikasi sebagai pekerjaan pasien yang terbanyak. Sementara dari riwayat pendidikannya, tamatan SLTA teridentifikasi sebagai yang terbanyak baik pada pasien laki-laki maupun perempuan.

Berdasarkan tempat (domisili), sebagian besar pasien berasal dari Kota Padang (64,1\%). Mengingat hemoptisis adalah keadaan yang menakutkan bagi pasien dan termasuk salah satu kegawatan paru maka pasien cenderung akan mencari pusat pelayanan yang aksesnya lebih dekat dari tempat tinggalnya secepat mungkin, sehingga hanya kasus yang tidak dapat tertanggulangi di daerah saja yang kemudian akan dirujuk ke rumah sakit pusat.

Angka kematian dari seluruh pasien dengan hemoptisis yang dirawat di bangsal paru RSUP Dr. M. Djamil Padang selama periode Januari 2011 Desember 2012 sebesar 6,8\% dari total kasus hemoptisis dengan jumlah 7 kasus. Hasil ini lebih sedikit bila dibandingkan dengan persentase jumlah kematian pada studi lain.

\section{KESIMPULAN}

1. Prevalensi kejadian hemoptisis di bangsal paru RSUP Dr. M. Djamil Padang periode Januari 2011 - Desember 2012 adalah 3,6\%.

2. Kejadian hemoptisis berdasarkan usia pasien terbanyak ditemukan pada kelompok usia 31 -40 tahun. 
3. Kejadian hemoptisis berdasarkan jenis kelamin pasien didominasi oleh laki-laki.

4. Kejadian hemoptisis berdasarkan riwayat pendidikan pasien yang paling banyak ditemukan adalah tamat SLTA.

5. Kejadian hemoptisis berdasarkan pekerjaan pasien paling banyak adalah ibu rumah tangga.

6. Kejadian hemoptisis berdasarkan tempat (domisili) pasien paling banyak berasal dari Kota Padang.

7. Kejadian hemoptisis berdasarkan klasifikasi hemoptisis pada pasien terbanyak adalah hemoptisis sedang.

8. Kejadian hemoptisis berdasarkan penyakit yang mendasari hemoptisis pada pasien paling banyak disebabkan oleh TB paru.

9. Angka kematian pasien dengan hemoptisis di bangsal paru RSUP Dr. M. Djamil Padang periode Januari 2011 - Desember 2012 sebesar $6,8 \%$ dari total kejadian hemoptisis.

\section{DAFTAR PUSTAKA}

1. Wibisono MJ, Alsagaff $H$. Batuk darah. Dalam: Wibisono MJ, Winariani, Hariadi $S$ editor (penyunting). Buku Ajar IImu Penyakit Paru 2010.Surabaya: Departemen IImu Penyakit Paru FK UNAIR-RSUD Dr. Soetomo; 2010. hlm. 74-87.

2. Swidarmoko B. Batuk darah (Hemoptisis). Dalam: Swidarmoko $B$, Susanto $A D$, editor (penyunting). Pulmonologi Intervensi dan Gawat Darurat Napas. Jakarta: Departemen Pulmonologi dan IImu Respirasi FK UI; 2010. hlm. 28-53.

3. Rasmin M. Editorial: Hemoptisis. J Respir Indo. 2009;29(2):53-4.

4. Sakr L, Dutau H. Massive hemoptysis: An update on the role of bronchoscopy in diagnosis and management. Respiration. 2010;80:38-58.

5. Kreit JW. Hemoptysis. Dalam: Albert RK, Spiro SG, Jett JR editor (penyunting). Clinical Respiratory Medicine. Edisi ke-3. Philadelphia: Mosby Elsevier; 2008. hlm. 311-36.

6. Ashraf $O$. Hemoptysis, a developing world perspective. BMC Pulmonary Medicine. 2006;6:1.

7. Abal AT, Nair PC, Cherian J. Haemoptysis: aetiology, evaluation and outcome-a prospective study in a third-world country. Respir Med. 2001;95(7):548-52.

8. Prasad R, Garg R, Singhai S, Srivastava P. Lessons from patients with hemoptysis attending a chest clinic in India. Ann Thorac Med. 2009;4(1):10-2.

9. Wihastuti R, Maria, Situmeang T, Yunus F. Profil penderita batuk darah yang berobat ke bagian paru RSUP Persahabatan Jakarta. J respir Indo. 1999;(19):54-9.

10. World Health Organization. Global tuberculosis report 2013. Tersedia dari: URL: HYPERLINK http://www.who.int/tb/publications/global_report/en

11. Departemen Kesehatan RI. Pengendalian TB di Indonesia mendekati target MDG. Tersedia dari: URL: HYPERLINK http://www.depkes.go.id /index.php?vw=2\&id=857

12. Russilawati, Chan Y, Taufik, Medison I, Khairsyaf O. Hemoptysis in regional referral hospital: a five years experience. Proceeding of the $13^{\text {th }}$ International Meeting on Respiratory Care Indonesia (Respina); 2011; Jakarta, Indonesia.

13. Hirshberg B, Biran I, Glazer M, Kramer MR. Hemoptysis: etiology, evaluation, and outcome in a tertiary referral hospital. Chest. 1997;112:440-4.

14. Bidwell JL, Pachner RW. Hemoptysis: diagnosis and management. Am Fam Physician. 2005;(72):1253-60.

15. Shigemura N, Wan IY, Yu SCH, Wong RH, Hsin MKY, Thung HK, et al. Multidisciplinary management of life-threatening massive hemoptysis: a 10-year Experience. Ann Thorac Surg. 2009;(87):849-53.

16. Dye C. Global epidemiology of tuberculosis. Lancet. 2006;367:938-40.

17. Valipour A, Kreuzer A, Koller H, Koessler W, Burghuber OC. Bronchoscopy-guided topical hemostatic tamponade therapy for the management of life-threatening hemoptysis. Chest. 2005;(127):2113-8.

18. Fartoukh M, Khalil A, Louis L. An integrated approach to diagnosis and management of severe haemoptysis in patients admitted to the intensive care unit: a case series from a referral centre. 
Respir Res. 2007;8:11-20.

19. Bhatta DR, Singh TSK, Gokhale S. Hemoptysis: is it tuberculosis?. Int J Infect Microbiol. 2012; 1(2):63-7.

20. Perhimpunan Dokter Paru Indonesia. Kanker paru: pedoman diagnosis \& penatalaksanaan di Indonesia; 2003.

21. Boyd M, Depriest K, Chin Jr. R, Chatterjee A, Miles $\mathrm{M}$, Conforti $\mathrm{J}$, et al. Hemoptysis in the advanced elderly. Chest. 2008;134(4). 